\title{
Spectroscopic Determination of Excitation Temperature and Electron Density in Premixed Laminar Flame
}

\author{
S.S. Hamed \\ Physics Department Faculty of Girls, Ain Shams University, Cairo Egypt
}

\begin{abstract}
Spectroscopic diagnostic technique are applied for the determination of excitation temperature $T_{\text {exc }}$ and electron density in Air - Acetylene premixed laminar flame. A group of FeI spectral lines has been used to estimate $T_{\text {exc }}$ using Boltzmann plot. Electron number density was determined from atom ion line pairs for $\mathrm{Cd}$ and $\mathrm{Zn}$ using Saha - Boltzmann equation after substitution the obtained value of excitation temperature. The obtained result of temperature show that the populations of energy levels follow Boltzmann's distribution law.
\end{abstract}

\section{Introduction:}

The atomization processes taking place in flames used as atom reservoir in analytical atomic absorption spectroscopy is considered as essential parameter that determines the absorption signal. The conditions with the flames depend mainly on the temperature and electron number density prevailing in the flame. These physical quantities describing the flame condition depend on some experimental parameters namely; fuel oxidant ratio, flow rates and design of the burner.

In flames burning at atmospheric pressure the primary reaction zone is extremely thin. Thus the residence time of the gases in this region is too short for the reaction between fuel and oxidant to reach completion or for thermodynamic equilibrium to be established. The region of interconal zone is much broader than the reaction zone; in such region the equilibrium is usually established via recombination of radicals and dissociation of the combustion products. This region of thermal equilibrium begins almost outside the reaction zone. The nature of the interconal zone for particular fuel / oxidant combinations varies considerably with the mixture strength. Consequently, this region is of interest for studies of the kinetics of flame processes, which depend mainly on excitation temperature in the flame. 
For the determination of the excitation temperature in flames sodium line reversal method is usually employed. [1,2,3] In this method sodium is added to the flame that is viewed through a spectroscope against a bright background continuum source. If the latter is operated to be hotter or colder than the flame, the sodium D lines will appear respectively either as dark lines in absorption or as bright light lines standing out against the the background. A reversal point is obtained when both source and flame are at the same temperature. This method requires special apparatus and are frequently time consuming.

Another widely used technique is the intensity measurement of spectral lines emitted by the flame, which, in case of local thermal equilibrium, is given by :

$$
I_{i j}=\frac{1}{4 \pi} \frac{h c}{\lambda} \frac{N_{o}}{U(T)} g_{i} A_{i j} e^{-E_{i} / K T}
$$

where $N_{o}$ is the total number density of atoms in the ground state.

$g_{i}$ the statistical weight of the upper level.

$E_{i}$ is the energy of the upper level

$U(T)$ is the partition function.

when oscillator strength $f_{i j}$ is introduced instead of transition probabilities $A_{i j}$, the equation takes the form

$$
I_{i j}=h \frac{e^{2}}{2 \lambda^{3}} \frac{N_{o}}{U(T)} \frac{g_{i} f_{i j}}{\varepsilon_{o} m_{e}} e^{-E_{i} / K T_{e x c}}
$$

where $\varepsilon_{o}$ is the permeability of free space.

$m_{e}$ the electron mass.

$e$ the electron charge.

According to the forgoing equation $T_{\text {exc }}$ can be determined using only one spectral line. However, this requires the determination of the absolute intensity, accurate values of transition probability, partition function and the knowledge of total number of atoms $N_{\mathrm{o}}$. To avoid these difficult $T_{\text {exc }}$ can be determined from the intensity ratio of two or more spectral lines belonging to the same ionization stage. In this case, the partition function, and the number 
density $N_{o}$ cancel, in addition there is no need to measure absolute intensity. In order to obtain accurate temperature values a number of spectral lines can be used. From the foregoing equation it can be seen that

$$
\log \frac{I \lambda^{3}}{g_{f}}=\text { Const. }-\frac{\mathrm{E}_{\mathrm{i}}}{\mathrm{KT}_{\mathrm{exc}}}
$$

Thus the plot of $\log \frac{I \lambda^{3}}{g f}$ or $\log \frac{I \lambda}{g A}$ versus the energy of the upper level $E_{i}$ yield a straight line, if the population of the energy states obey Boltzmann distribution law. The straight lines is called Boltzmann plot. Its slope equals $-\frac{1}{K T_{e x c}}=-\frac{0.625}{T_{e x c}}$ if $E_{i}$ is taken in $\mathrm{cm}^{-1}$ or $-5040 / \mathrm{T}$ if $E_{i}$ is in $\mathrm{eV}$.

The electron density, on the other hand can be determined by apply Saha equation from which the ratio of the intensity of an atom line $I_{a}$ to that of an ion $\mathrm{I}_{\mathrm{i}}$ belonging to the next ionization stage of the element is given by

$$
\frac{I_{i}}{I_{a}}=\frac{1}{n_{e}} 2\left(\frac{2 \pi m k}{h^{2}}\right)^{3 / 2} \frac{g_{i} A_{i} \lambda_{a}}{g_{a} A_{a} \lambda_{i}} T_{i o n}{ }^{3 / 2} \exp \frac{-E_{\text {ion }}+\Delta E_{\text {ion }}}{K T_{\text {ion }}} \exp \frac{E_{a}-E_{i}}{K T_{\text {exc }}}
$$

From which the electron density $\left(\mathrm{n}_{\mathrm{e}}\right)$ can be determined.

In the present work spectroscopic diagnostic technique are applied for the determination of excitation temperature and electron density in premixed laminar flame. The excitation temperature is measured using group of $\mathrm{Fe}$ I spectral lines [4] while the electron density is determined from the intensity ratio of atom / ion line pairs of $\mathrm{Cd}$ and $\mathrm{Zn}$.[5]

\section{Experimental:}

\subsection{Experimental Set up:}

Perkin-Elmer atomic absorption spectrometer model (2280) equipped with burner nebulizer for an air - acetylene flame having single slot $100 \mathrm{~mm}$ was used. The dispersive element of the monochromator is plane grating having 1800 line $/ \mathrm{mm}$ blazed at $255 \mathrm{~nm}$. The monochromator has a focal length equal $267 \mathrm{~mm}$ equipped with a photomultipler and a digital read out system. 


\subsection{Spectral Lines for Excitation Temperature:}

Table (1) gives the wavelengths and the atomic constants of $7 \mathrm{Fe} \mathrm{I}$ spectral lines. For These lines at least 12 sources for the oscillator strength values are available. For the determination of $\mathrm{T}_{\mathrm{exc}}$ of the present flame cell these sets of oscillator strengths were applied to construct the Boltzmann plot. For this purpose a computer linear regression program ( Segma plot ) was used, that gives the slope of the straight line Boltzmann plot as well as the error in the slope $\Delta \mathrm{S}$ that originates from the scatter of the experimentally determined line intensities. Accordingly both $\mathrm{T}_{\mathrm{exc}}$ and the error $\Delta \mathrm{T}_{\mathrm{exc}}$ could be determined for each set of gf values, the most appropriat set of gf values was chosen that yields the smallest values of $\Delta \mathrm{T}_{\mathrm{exc}}$.

Table (1): Fe I emission Line data.

\begin{tabular}{|c|c|c|c|c|c|c|c|c|c|c|c|c|c|}
\hline \multirow{2}{*}{$\lambda(\mathrm{nm})$} & \multirow{2}{*}{$\mathrm{E}\left(\mathrm{cm}^{-1}\right)$} & \multicolumn{9}{|c|}{ Log $g f$} \\
\cline { 4 - 13 } & & CT & CB & MS & C & R etal & K & AA & J & VS & BK & HP & BH \\
\hline 371.9 & 26875 & -0.32 & -0.29 & -0.54 & -0.54 & -0.17 & -0.54 & -0.51 & -0.27 & -0.20 & -0.43 & -0.43 & -0.45 \\
\hline 372.3 & 27560 & -1.02 & -1.08 & -1.28 & -1.33 & -1.02 & -1.18 & -1.22 & -0.92 & -1.03 & -1.28 & -1.22 & -1.28 \\
\hline 273.5 & 33695 & 0.57 & 0.62 & 0.35 & 0.40 & 0.57 & 0.41 & 0.38 & 0.67 & 0.52 & 0.31 & 0.30 & 0.23 \\
\hline 273.7 & 27167 & -0.50 & -0.49 & -0.66 & -0.67 & -0.31 & -0.62 & -0.64 & -0.35 & -0.35 & -0.57 & -0.57 & -0.60 \\
\hline 374.8 & 27560 & -0.87 & -0.83 & -1.04 & -1.08 & -0.76 & -1.00 & -1.04 & -0.72 & -0.79 & -1.01 & -0.98 & -1.06 \\
\hline 374.9 & 34040 & 0.44 & 0.43 & 0.20 & 0.24 & 0.41 & 0.30 & 0.29 & 0.57 & 0.39 & 0.17 & 0.18 & 0.09 \\
\hline 375.8 & 34329 & 0.31 & 0.34 & 0.03 & 0.07 & 0.22 & 0.18 & 0.31 & 0.45 & 0.26 & 0.00 & 0.00 & -0.03 \\
\hline
\end{tabular}

CT: Corliss \& Tech [6]

CB: Corliss \& Bozman [7]

MS: Margoshes \& Scribner [8]

C : Crosswhite [9]

$\mathrm{R}_{\text {etal: }}$ Reif \& Fassel and Knisely[10]

K: King [11]
AA: Allen \& Asaad [12]

J: Jurgens [13]

VS: Valters \& Startsev [14]

BK: Bridges \& Kornblith [15]

HP: Huber \& Parkinson [16]

BH: Banfield \& Huber [17]

\section{Spectral Lines for Determination of Electron Density:}

For the determination of the electron number density in the flame under investigation, atom /ion line pairs of elements that have measured values of transition probabilities were selected. In the present work atom / ion line pairs of $\mathrm{Cd}$ and $\mathrm{Zn}$ will available. There $\mathrm{E}$ and $\mathrm{gA}$ values are given in Table (2). For these line pairs transition probabilities determined by two outhers are given in Table (2). 
Table (2): $\mathrm{Cd} \& \mathrm{Zn}$ Data for electron density measurement.

\begin{tabular}{|l|l|l|l|l|}
\hline \multirow{2}{*}{ Species } & \multirow{2}{*}{$\lambda(\mathrm{nm})$} & \multirow{2}{*}{$\mathrm{E}\left(\mathrm{cm}^{-1}\right)$} & \multicolumn{2}{|c|}{$g_{a} A_{a} \lambda_{i} / g_{i} A_{i} \lambda_{a}$} \\
\cline { 5 - 5 } & & & Ratios \\
\cline { 3 - 5 } & & 43692 & BS \\
\hline Cd I & 228.802 & 2.6575 & 3.3949 \\
\hline Cd II & 226.502 & 44136 & & 2.5203 \\
\hline Zn I & 213.86 & 46745 & 3.0290 & \\
\hline
\end{tabular}

AS: Andersen \& Sorensen [18]

BS: Bauman \& Smith [19]

\section{Results and Discussion:}

\subsection{Optimal Condition:}

The flame under investigation is used as an atom cell for atomic absorption spectroscopy measurements [20, 21]. For this reason it is worth to carry out that the spectroscopic diagnostic measurements under the optimal conditions of the flame as an atom reservoir. The parameters that control the flame conditions are the flow rates of fuel (acetylene), oxidant (air) and height of burner.

Optimal values of these parameters are considered those that yield the high value of absorption. It was observed that the optimal values for the flow rate of air and acetylene are $9.35 \mathrm{~L} / \mathrm{min}$ and $0.7 \mathrm{~L} / \mathrm{min}$ respectively; the values of the vertical and horizontal burner height are $17.5 \mathrm{~mm}$ and $20 \mathrm{~mm}$ respectively.[22]

\subsection{Atom Excitation Temperature:}

Solution containing $200 \mu \mathrm{g} / \mathrm{ml} \mathrm{Fe}$ was aspirated into the flame set at the previous obtained optimal conditions for the determination of $T_{\text {exc. }}$ Table (3) gives the results obtained for the excitation temperature $T_{\mathrm{exc}}$ from the measuring intensity of the selected Fe spectral line after the substitution with all available sets of transition probabilities. It can be seen that two values of calculated $\mathrm{T}_{\mathrm{exc}}$ may have nearly the same values, while the correction $\Delta \mathrm{T}$ may differ significantly according to the set of transition probability. Figures (1\&2) show an example for the Boltzmann plot obtained using the $g f$ values according to Jurgens [13] and King [11] 
Table (3): Results obtained for flame temperature measurements

\begin{tabular}{|c|c|c|}
\hline $\begin{array}{c}\text { Reference of } g f \\
\text { values }\end{array}$ & Temperature $(\mathrm{T})$ & $\Delta \mathrm{T}_{\text {exc }}$ \\
\hline CT & 2485.89 & 68.94 \\
\hline CB & 2607.54 & 98.03 \\
\hline MS & 2555.20 & 66.07 \\
\hline C & 2457.28 & 83.43 \\
\hline$R_{\text {etal }}$ & 2743.20 & 125.49 \\
\hline K & 2719.52 & 473.46 \\
\hline AA & 2392.54 & 105.17 \\
\hline J & 2465.09 & 50.77 \\
\hline VS & 2707.27 & 119.60 \\
\hline BK & 2710.14 & 122.48 \\
\hline HP & 2745.45 & 97.70 \\
\hline BH & 2776.09 & 128.99 \\
\hline
\end{tabular}

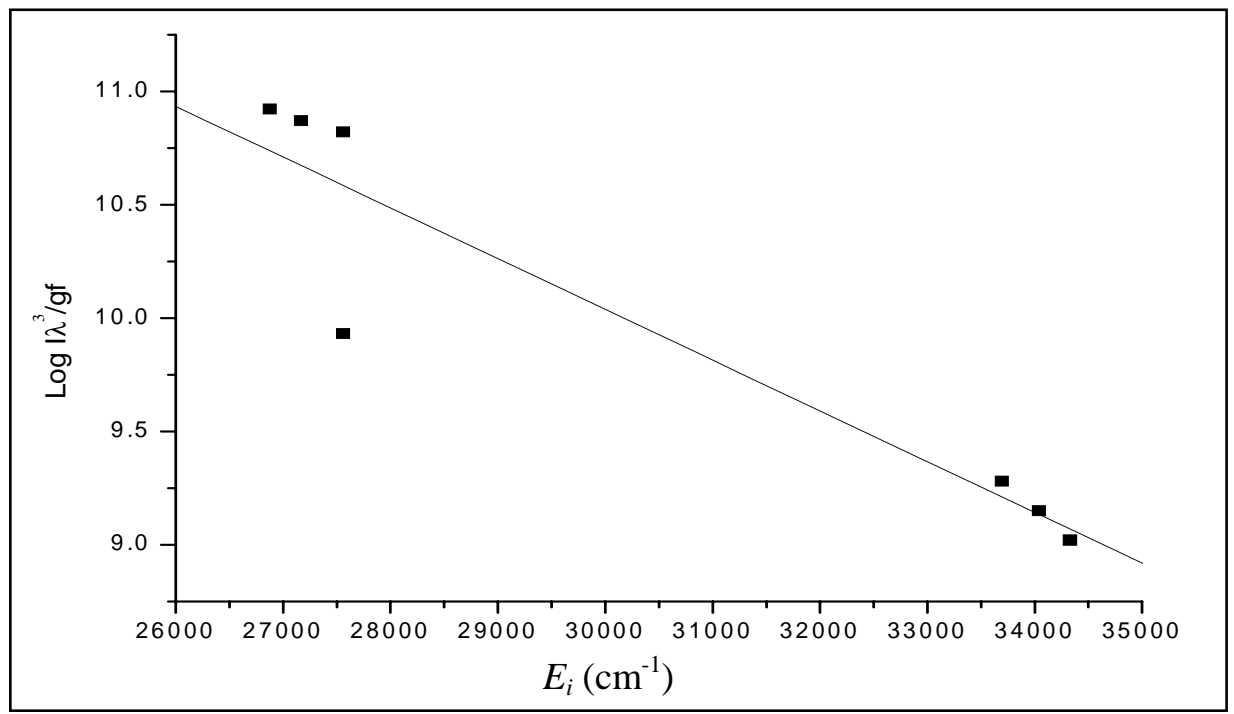

Fig. (1): Boltzmann plot according to King values of gf. 


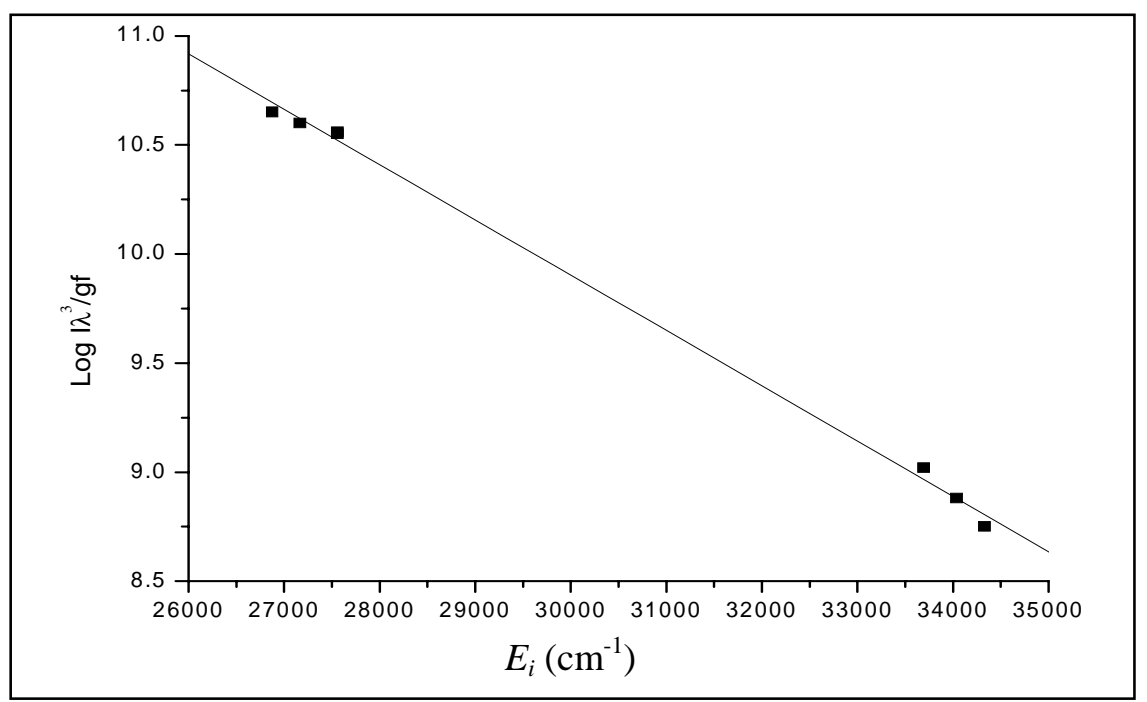

Fig. (2): Boltzmann plot according to Jurgens values of gf.

\section{Electron Density Measurement:}

For the determination of electron density in the flame, standard solution containing $200 \mu \mathrm{g} / \mathrm{ml}$ for $\mathrm{Cd}$ and $\mathrm{Zn}$ was nebulized at the previous optimal condition. The intensity of atom (I) and ion (II) lines for the two elements chosen was measured. The calculation of the electron density was carried out under the assumption that the flame is in local thermodynamic equilibrium (LTE). So the substitution for the ionization temperature $\left(\mathrm{T}_{\mathrm{ion}}\right)$ by the same value obtained for the excitation temperature $\left(\mathrm{T}_{\text {exc }}\right)$, according to Jurgens $g_{f}$ values, in equ.(3) the electron number density can be determined. Table (4) illustrates the obtained electron density for the two sets of the available transition probabilities. It can be seen from the table that the results are in good agreement with each other.

Table (5): Results obtained for electron density measurement

\begin{tabular}{|c|c|c|}
\hline Species & Reference of gA values & Electron density $\left(\mathrm{cm}^{-3}\right)$ \\
\hline $\mathrm{Cd}$ & \multirow{2}{*}{$\mathrm{AS}$} & $4.770 \times 10^{13}$ \\
\cline { 1 - 1 } $\mathrm{Zn}$ & \multirow{2}{*}{$\mathrm{B}$} & $0.862 \times 10^{13}$ \\
\cline { 1 - 1 } $\mathrm{Cd}$ & \multirow{2}{*}{$\mathrm{Zn}$} & $3.750 \times 10^{13}$ \\
\cline { 1 - 1 } & & $1.039 \times 10^{13}$ \\
\hline
\end{tabular}




\section{Conclusions:}

- From the results obtained in the present work it can be seen that straight lines obtained for the Boltzmann plots for $\mathrm{Fe}$ I lines show that the population distribution over the energy levels follow Boltzmann's law.

- In the Air- $\mathrm{C}_{2} \mathrm{H}_{2}$ flame the excitation is thermal with a temperature around $2400 \mathrm{~K}^{0}$.

- The obtained excitation temperature was in good agreement with that obtained experimentally by continuum atomic absorption method. [23]

- The calculated electron densities for $\mathrm{Cd}$ from the two sets of $\mathrm{gA}$ used are in good agreement with each other as well as from $\mathrm{Zn}$.

\section{References:}

1. A.G. Gaydon and H.G. Wolfhard, "Flames, Their Structure, Radiation and Temperature", Chapman and Hall, London, 3 rd ed., (1970).

2. R.H. Tourin, "Spectroscopic Gas Temperature Measurements", Elsevier, Amsterdam, (1966).

3. G.F. Kirkbright, M. Sargent and S. Vetter, Spectrochim. Acta, 25B, 465 (1970).

4. M.A.Eid, El Bialy, M.H. Abdallan, H.H.Higazy and S.S. Hamed, Canadian J. Spectroscopy, 35, (1), (1990).

5. D.J. Kalnicky, V.A. Fassel and R.N. Kniselely, Applied Spec. 31 (1977).

6. C.H. Corliss and J.L. Tech "Transition Probabilities for 3228 lines of Fe I," Nat. Bur. Stand., Monograph 108 (1968).

7. C.H.Corliss and W.R. Bozman "Experimental Transition Probabilities for Spectral lines of Seventy Elements", Nat. Bur. Stand. Monograph 53 (1962).

8. M.Margoshes and B.F. Scribner, J.Res. Nat. Bur. Stand., 67A, 561 (1963).

9. H.M. Crosswhite, "The Spectrum of Fe I', The Johns Hopkins University Press, Baltimore, (1958).

10. I.G. Reif, V.A. Fassel and R.N. Kinseley, Reprints $16^{\text {th }}$ Coll. Spectrosc. Int., Heidtberg, vol. 2, Hilger, London, (1970).

11. R.B. King and A.S. King, Astrophys. J. 87, 24 (1983).

12. C.W.Allen and A.S.Asaad, Monthly Notices Roy. Aastron. Soc. 117, 36 (1657).

13. G. Jurgens, Z. Physik, 138, 613 (1954).

14. A.K. Valters and G.P. Startsev, Opt. Spectrosc. (USSR), 17, 265 (1964).

15. J.M. Bridges and R.L. Kornblith, Astrophys. J. 192, 793 (1974).

16. M.C.E. Huber and W.H. Parkinson, Astrophys. J. 192, 793 (1974).

17. F.B. Banfield and M.C.E. Huber, Astrophys. J. 186, 335, (1973). 
18. T. Andersen, J. Desesquelles, K.A. Jensen, and G. Sorensen, J. Opt. Soc. Am. 60, 1199 (1970).

19. S. R. Bauman and W.H. Smith, J. Opt. Soc. Am. 60, 345 (1970).

20. R.Sinem Atgin, O.El-Agha, A. Zararsiz, A.Kocatas, H. Parlak,and G.Tuncel, Spectrochimica Acta Part B55, 1151 (2000).

21. U. Drivikli and L. Elci, Analyti. Chim. Acta, 452 (2), 231 (2002).

22. A.B. El Bialy, S.S. Hamed, W.M. Moussa and R.K. Abd El-Hameed, Egypt. J. Solids (28), 151 (2005).

23. R. F. Browner and J. D. Winefordner, Analytical Chemistry 44 (2). 247 (1972). 